\title{
AVALIAÇÃO DOS EFEITOS DA Curcuma longa L. SOBRE A GLICEMIA DE RATOS WISTAR ALIMENTADOS COM DIETA DE CAFETERIA
}

\section{EVALUATION OF EFFECTS OF CURCUMa longa L. ON GL YCEMIA OF WISTAR RATS FED WITH CAFETERIA DIET}

\author{
João Pedro Alves De Oliveira ${ }^{1}$, Pâmela Morais Bacelar ${ }^{1}$, Mariane Aline Gomes \\ Oliveira ${ }^{1}$, Gustavo Frederico Moreno ${ }^{2}$, Sara Coletti Pinto ${ }^{2}$, Sóstenez Alexandre \\ Vessaro Silva ${ }^{3}$, Daniela Miotto Bernardi $4^{*}$
}

\footnotetext{
${ }^{1}$ Nutricionista, Centro Universitário Fundação Assis Gurgacz (FAG). ${ }^{2}$ Veterinário, Centro Universitário Fundação Assis Gurgacz (FAG). ${ }^{3}$ Biólogo, Doutor em Biologia das interações orgânicas, Docente do Curso de Nutrição, Centro Universitário Fundação Assis Gurgacz (FAG), ${ }^{4}$ Nutricionista Doutora, Docente do Curso de Nutrição, Centro Universitário Fundação Assis Gurgacz (FAG),

* Autor correspondente: danimiottober@gmail.com, https://orcid.org/0000-0001-9019-3835
}

\section{RESUMO}

A Curcuma longa L. é popularmente conhecida como cúrcuma e possui um composto bioativo chamado curcumina. No presente estudo, o objetivo foi avaliar o efeito da cúrcuma sobre a glicemia e crescimento de ratos Wistar. Foram utilizados 16 ratos machos, sendo divididos em 4 grupos de 4 animais, sendo grupo RC alimentados com ração comercial, grupo DC alimentados com dieta de cafeteria, grupo DC2C alimentados com dieta de cafeteria $+2 \%$ de cúrcuma adicionada na dieta e grupo DC5C com dieta de cafeteria $+5 \%$ de cúrcuma adicionada à dieta. Foi avaliado 0 consumo de ração diário (CRD), ganho de peso diário (GPD), conversão alimentar (CA), peso de órgãos (rim e baço) e a glicemia dos animais. Os resultados mostraram que houve diferença significativa $(p<0,05)$ no CRD, GPD, CA, peso de rim e baço, sendo que os animais alimentados com dieta de cafeteria os que apresentaram maior eficiência na dieta. A glicemia sérica não diferiu estatisticamente entre os tratamentos $(p>0,05)$. São necessários mais estudos para compreender o efeito da cúrcuma na dieta.

Palavras chave: açafrão; glicemia; nutrição.

\begin{abstract}
Curcuma longa $L$. is popularly known as turmeric and has a bioactive compound called curcumin. The objective of this study was to evaluate the effect of turmeric on the glycemia and growth of Wistar rats. Sixteen male rats were divided into 4 groups of 4 animals, being CF group fed fed with commercial feed, CD group fed with cafeteria diet, CD2C group fed with cafeteria diet $+2 \%$ turmeric and CD $5 C$ group with cafeteria diet + 5\% turmeric. Daily dietary intake (DDI), daily weight gain (DWG), feed conversion (FC), body weight (kidney and spleen) and serum glycemia of the animals were evaluated. The results showed that there was a significant difference $(p<0.05)$ in DDI, DWG, FC, kidney and spleen weight. The animals fed with a cafeteria diet showed the highest efficiency in the diet. Serum glycemia did not differ statistically between treatments ( $p>0.05)$. Further studies are needed to understand the effect of turmeric on diet.
\end{abstract}

Key words: turmeric; glycemia; nutrition. 


\section{INTRODUÇÃO}

O alimento funcional vai além da função de fornecer energia e nutrientes essenciais, em quantidades equilibradas, para a promoção do crescimento normal e evitar desequilíbrios nutricionais (PACHECO et al. 1999). Segundo Basho et al.. (2010), alimentos funcionais além de fornecerem nutrientes básicos na dieta, apresentam benefícios para o funcionamento metabólico e fisiológico, prevenindo doenças crônicas degenerativas.

Entre os alimentos funcionais, destaca-se a Curcuma longa $L$., também conhecida como cúrcuma, gengibre dourado ou açafrão da Índia, que é uma espécie originária do sudeste asiático e amplamente cultivada no local, pertencente à família das Zingiberaceae, tem pequeno porte, uma vez que, mede aproximadamente $1 \mathrm{~m}$ (VILELA; ARTUR, 2008).

Comercialmente, a cúrcuma utilizada como uma especiaria devido ao seu sabor forte, por apresentar coloração amarelada marcante, e uma fonte de amido industrial (VILELA; ARTUR, 2008). Os componentes químicos da Cúrcuma longa L., possuem atividade antimicrobiana e antioxidante significativo (NAM et al., 2014). Sua alta atividade antioxidante está correlacionada ao número de grupos hidroxilas na estrutura 11 do seu anel aromático (ROSSI et al., 2008; HAMAGUCHI; ONOL; YAMADA, 2010).

Sugere-se que o mecanismo hipoglicemiante da Curcuma longa $L$. deve-se ao efeito da curcumina, um composto da cúrcuma, sobre a estimulação sobre células betas pancreáticas e, portanto, sobre secreção de insulina (WICKENBERG et al. 2010). Segundo Wickenberg et et al. (2010) a ingestão de $6 \mathrm{~g}$ de cúrcuma aumentaram as concentrações de insulina no soro pós-prandial sem afetar significativamente os níveis de glicose plasmática em humanos.

A dieta de cafeteria é composta de: patê, bacon, batata chips, biscoito, chocolate e ração comercial (CHAMPION et al 2004). Esse modelo de dieta experimental pode simular a dieta ocidental devido à alta densidade calórica, e a grande quantidade de gorduras e açúcares (CHAMPION et al2004). Segundo Ferreira (2010) a dieta consumida no ocidente pode acarretar o desenvolvimento de obesidade, além de doenças, como diabetes tipo II e doenças cardiovasculares. Portanto, dieta de cafeteria é um modelo de dieta adequado para avaliar os efeitos da cúrcuma sobre a glicemia.

Nesse contexto, o objetivo do presente estudo será avaliar o efeito sobre a glicemia e crescimento da inclusão de Curcuma longa $L$. na alimentação de ratos tratados com dieta de cafeteria.

\section{METODOLOGIA}

O experimento foi realizado após aprovação pelo comitê de ética, parecer CEUA/FAG № 001/2017, e seguiu todos os requisitos éticos do Colégio Brasileiro de Experimentação Animal (COBEA).

No estudo foram utilizados 16 ratos recém-desmamados, machos, da espécie Rattus Norvegicus linhagem Wistar, com vinte e um dias de vida, obtidos do Biotério do Centro Universitário Fundação Assis Gurgacz.

O experimento teve duração total de 60 dias, e durante o período experimental os animais foram mantidos em gaiolas individuais, à temperatura ambiente, ciclo de claro escuro (12 horas claro/ 12 horas escuro) com água e alimentação ad libitum. 
Os animais foram divididos em 4 grupos de 4 animais, distribuídos conforme descrito na Figura 01.

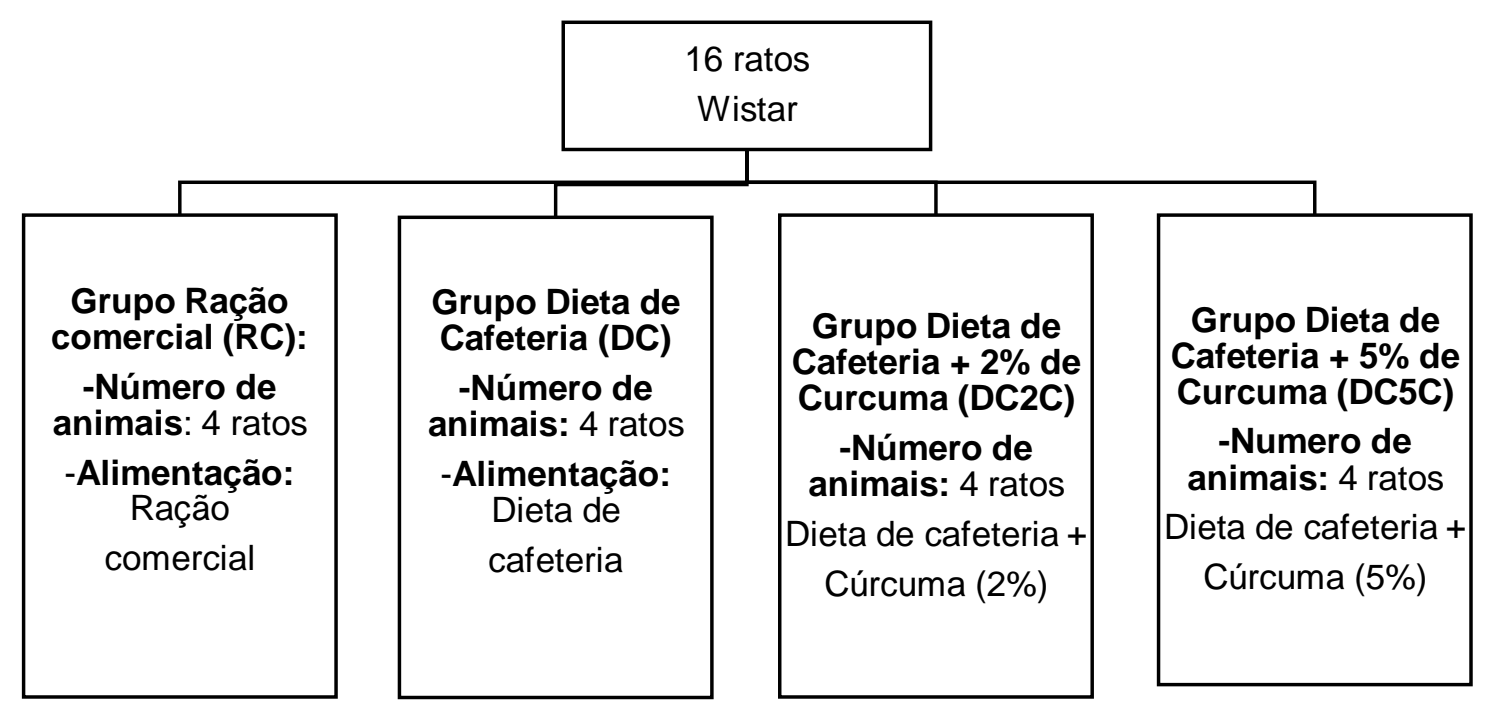

Figura 01. Delineamento experimental

A ração comercial utilizada foi a linha Biotec da marca BioBase. As demais dietas experimentais foram produzidas no laboratório de Análises Físico-químicas, do Centro Universitário Fundação Assis Guargacz.

A dieta de cafeteria é composta de: patê, bacon, batata chips, biscoito, chocolate e ração comercial (CHAMPION et al 2004). Utiliza-se este modelo de dieta devido a sua alta densidade calórica e grandes quantidades de açúcares e gorduras, assemelhando o consumo dos ratos com a dieta moderna ocidental consumida atualmente pela maioria da população. A descrição dos ingredientes e das respectivas quantidades utilizadas na dieta de cafeteria encontra-se na tabela 01.

Tabela 01 - Ingredientes utilizados na dieta experimental de ratos.

\begin{tabular}{cccc}
\hline Ingredientes & DC $(\mathrm{g})$ & DC2C $(\mathrm{g})$ & DC5C $(\mathrm{g})$ \\
\hline Ração comercial & 142,85 & 142,85 & 142,85 \\
Biscoito doce & 142,85 & 142,85 & 142,85 \\
Batata palha & 142,85 & 142,85 & 142,85 \\
Chocolate ao & & & \\
leite & 142,85 & 142,85 & 142,85 \\
Bacon & 142,85 & 142,85 & 142,85 \\
Patê & 285,7 & 285,7 & 285,7 \\
Cúrcuma & - & 20 & 50 \\
\hline
\end{tabular}

DC: Dieta de Cafeteria; DC2C: Dieta de Cafeteria + 2\% de Cúrcuma; DC5C: Dieta de Cafeteria + 5\% de Cúrcuma; Quantidade em gramas (g) para $1 \mathrm{~kg}$ de ração.

A cúrcuma em pó usada na dieta de dois grupos experimentais foi adquirida comercialmente em um celeiro da cidade de Cascavel-PR, e foi adicionada na dieta do grupo DC2C a quantia de $2 \%$ e para o grupo DC5C a quantia de $5 \%$, em relação à quantidade total da dieta (QURESHI, et al., 1992). Os demais ingredientes foram 
adquiridos no mercado local de Cascavel-PR, sendo a ração comercial da marca BioBase, biscoito doce da marca Isabela $\AA$, batata palha da marca Q-Delícia $\AA_{\text {, }}$ chocolate ao leite da marca Harald $\AA$, bacon da marca Adele $\AA$, patê da marca Seara $\AA$.

Os ingredientes da dieta foram previamente pesados em balança analítica (Viamart, modelo S $5000 \mathrm{C}$ ), e triturados em liquidificador industrial (marca Poli), após, foram misturados em uma bacia e peletizados manualmente. Todas as dietas experimentais foram secas em estufa de circulação de ar (Ethik Tecnology, modelo $400-8 D$ ) por três dias, a temperatura de 50 a $55^{\circ} \mathrm{C}$.

O período experimental teve duração de 60 dias, os animais foram pesados no início do período experimental, a cada sete dias e um dia antes do término do período experimental. As dietas e a água eram repostas a cada dois dias, sendo a dieta sempre pesada.

Com o peso das dietas e dos animais feitos separadamente, calculou-se o consumo de ração diária (CRD), ganho de peso diário (GPD) e consumo alimentar (CA). Os dados foram tabulados e as médias e desvio padrão calculadas pelo programa Microsoft Office Excel 2016. A conversão alimentar (CA) foi obtida a partir do da fórmula $C A=C R D / G P D$.

Após o término dos 60 dias de experimento, os animais ficaram em dieta hídrica nas 12 horas que precederam a eutanásia, sendo esta realizada sob supervisão de um médico veterinário. Os animais foram anestesiados com isoflurano com concentração de $100 \%$, por via inalatória e eutanasiados por meio de decapitação com uso da guilhotina.

A coleta de sangue foi realizada no momento da eutanásia, sendo colocado em frascos com fluoreto de sódio, e centrifugado em centrífuga da marca CELM, modelo LS - 3 plus, a $3000 \mathrm{rpm}$ por 20 minutos. O material centrifugado foi utilizado para análise de glicemia, o sangue foi passado no espectrofotômetro da marca Bioplus, um equipamento semi-automatizado e foi utilizado o kit comercial da marca Cralplast.

Após a decapitação e coleta do sangue, cada animal foi colocado em posição decúbito dorsal sobre mesa cirúrgica para o procedimento de laparatomia, para realização da retirada e pesagem dos rins e baço em balança semi analítica da marca Shimadzu.

Para tabulações dos dados, foi utilizado o programa Microsoft Office Excel 2016. Para verificação das diferenças entre os grupos experimentais, foram testadas estaticamente por análise de variância (ANOVA), com teste de médias de Tukey em valores significativos. Os valores considerados foram de probabilidade $p<0,05$.

\section{RESULTADOS E DISCUSSÕES}

\subsection{CONSUMO DE RAÇÃO E CRESCIMENTO DOS ANIMAIS}

Apresentam-se os dados na tabela 02 de consumo diário de ração (CDR), ganho de peso diário dos animais (GPD), conversão alimentar (CA) e peso do rim e baço. A tabela demonstra que o GPD teve diferença estatística $(p<0,005)$ entre os tratamentos, sendo que o grupo RC teve maior ganho de peso, o que pode ser explicado pelo fato da ração comercial ser mais palatável para os animais do que a dieta de cafeteria. Segundo Piva et al. (2016), por possuir um maior aporte calórico, a dieta de cafeteria tem um poder maior de saciedade, o que possivelmente resulta em menor consumo de ração e, portanto, menor ganho de peso por ter ingerido menor quantidade de ração. 
Tabela 02 Ganho de peso diário, conversão alimentar, consumo de ração diário, peso de rim e baço.

\begin{tabular}{cccccc}
\hline Tratamento & GPD $(\mathrm{g})$ & $\mathrm{CA}$ & $\mathrm{CRD}(\mathrm{g})$ & $\mathrm{RIM}(\mathrm{g})$ & $\mathrm{BAÇO}(\mathrm{g})$ \\
\hline $\mathrm{RC}$ & $3,82 \pm 0,36 \mathrm{~A}$ & $4,57 \pm 0,13 \mathrm{~A}$ & $17,48 \pm 1,70 \mathrm{~A}$ & $2,17 \pm 0,17 \mathrm{~A}$ & $0,53 \pm 0,05 \mathrm{~A}$ \\
$\mathrm{DC}$ & $2,91 \pm 0,60 \mathrm{AB}$ & $3,20 \pm 0,28 \mathrm{~B}$ & $9,22 \pm 1,33 \mathrm{~B}$ & $1,64 \pm 0,08 \mathrm{~B}$ & $0,39 \pm 0,02 \mathrm{~B}$ \\
$\mathrm{DC} 2 \mathrm{C}$ & $2,65 \pm 0,31 \mathrm{~B}$ & $3,45 \pm 0,16 \mathrm{BC}$ & $9,12 \pm 0,88 \mathrm{~B}$ & $1,48 \pm 0,16 \mathrm{~B}$ & $0,33 \pm 0,03 \mathrm{~B}$ \\
DC5C & $2,24 \pm 0,34 \mathrm{~B}$ & $3,76 \pm 0,14 \mathrm{C}$ & $8,44 \pm 1,29 \mathrm{~B}$ & $1,36 \pm 0,12 \mathrm{~B}$ & $0,33 \pm 0,10 \mathrm{~B}$ \\
Valor p & 0,005 & $<0,001$ & 0,00001 & 0,0007 & 0,001 \\
\hline
\end{tabular}

RC: grupo 1 ração comercial; DC: grupo 2 dieta de cafeteria; DC2C: grupo 3 dieta de cafeteria $+2 \%$ de cúrcuma; DC5C: grupo 4 dieta de cafeteria $+5 \%$ de cúrcuma; GPD: ganho de peso diário; CA: conversão alimentar; CRD: consumo de ração diário. Letras maiúsculas nas colunas representam diferença de médias pelo teste de Tukey.

No CRD, o grupo RC ingeriu uma quantidade significativamente maior que os grupos DC, DC2C e DC5C. No estudo de Arcaro Filho (2014), em seu experimento com ratos diabéticos tratados com administração de cúrcuma na ração, tiveram menor consumo da mesma, podendo assim, a cúrcuma, ter um possível poder de saciedade.

A CA foi utilizada para ver quanto o animal ingeriu de ração para haver um ganho de peso, quanto menor a CA maior eficiência da ração. Ao analisarmos a tabela, observamos que o grupo DC foi o que a ração se mostrou mais eficaz no consumo para ganho de peso com diferença significativa $(p<0,001)$, isso pode ter acontecido por causa do grande aporte calórico que possui a dieta de cafeteria (PIVA et al., 2016), assim, os animais do grupo DC ingeriram menos ração, mas a mesma se mostrou mais eficiente para ganho de peso.

No peso dos órgãos, no rim observou-se que na dieta $\mathrm{RC}$ teve maior peso do órgão, tendo diferença significativa $(p<0,0007)$ dos demais tratamentos. $O$ grupo DC5C foi o que apresentou menor peso entre os grupos, a dieta de cafeteria pode levar a uma complicação renal, pois aumenta os níveis de glicose sanguínea causando a diabetes mellitus e em longo prazo causar complicações. Segundo Viana et al., (2010) a nefropatia diabética é uma complicação crônica do diabetes, sendo uma das principais causas dos novos casos de diálise e está associada ao aumento da mortalidade nos pacientes.

O mesmo aconteceu com o baço sobre o tratamento RC ter maior peso do órgão que os demais tratamentos, havendo também uma diferenciação significativa $(\mathrm{p}<0,001)$.

\subsection{GLICEMIA SÉRICA}

Para obter resultados voltados à glicemia sérica dos animais, foi utilizada a dieta de cafeteria, que devido à sua composição deveria promover significativo aumento na glicemia (CHAMPION et al 2004), entretanto, conforme demonstrado na Figura 02, este modelo não foi eficiente em promover aumento da glicemia sérica aos animais. Em relação à cúrcuma, também não foram observados efeitos significativos de sua administração na dieta, portanto, conforme verificado na figura 02 , os tratamentos não apresentaram resultados de diferenciação significativa $(p>0,05)$. 


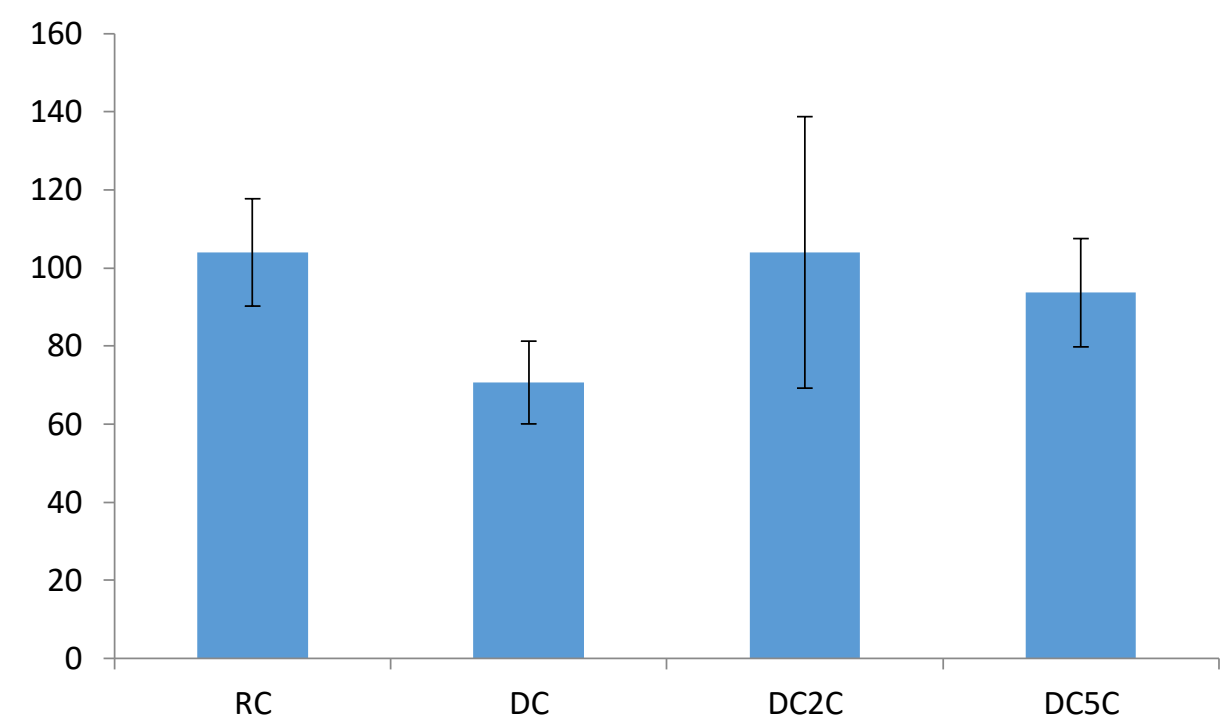

Figura 02 - Glicemia sérica (mg/dL) em jejum de12 horas. RC: grupo 1 controle; DC: grupo 2 dieta de cafeteria; DC2C: grupo 3 dieta de cafeteria + 2\%de cúrcuma; DC5C: grupo 4 dieta de cafeteria $+5 \%$ de cúrcuma.

No estudo mostrado por Arcaro Filho (2014), o tratamento com 90mg de curcumina $/ \mathrm{kg}$ foi capaz de promover redução na glicemia de animais diabéticos já no $10^{\circ}$ dia de tratamento, chegando à redução de $50 \%$ ao final do experimento de 45 dias.

Segundo Sartorelli; Franco (2003) entre 1988 e 1996, teve um grande aumento de alimentos com grandes quantidades de açúcares, ácidos graxos saturados e o consumo de refrigerantes, tendo redução de alimentos com carboidratos complexos, frutas, verduras e legumes nas regiões metropolitanas do Brasil. Grande parte desses alimentos foi utilizada para compor a dieta de cafeteria, provocando tendência para o aparecimento de diabetes.

Porém, não se obteve diferença significativa $(p>0,05)$ nos resultados de nosso presente estudo, talvez com maior tempo de experimento e/ou maior número de animais poderíamos ter tido resultados estatisticamente diferentes, pois foi utilizado um número reduzido de animais, apenas 4 por grupo, isso pode ter acarretado em nossos resultados negativos.

\section{CONCLUSÃO}

O CRD e GPD mostraram diferenças significativas, o grupo RC foi o que mais ganhou peso e consumiu ração em relação aos grupos experimentais. Ao analisarmos a CA, observamos que deu diferença significativa no grupo DC sendo o destaque, mostrando que a dieta de cafeteria foi consumida menos pelos animais, mas teve uma maior eficiência no ganho de peso. Isso pode ter acontecido pelo fato da dieta de cafeteria ser mais calórica e assim os animais ingerirem menos ração e tendo um aumento de peso maior.

O presente estudo mostrou que a administração de cúrcuma não promoveu efeito significativo sobre a glicemia, podendo o número reduzido de animais no experimento ter contribuído para este resultado. Estudos recentes mostram o efeito benéfico da cúrcuma sobre glicemia. 


\section{REFERÊNCIAS}

ARCARO FILHO, Carlos Alberto. Atividade antidiabética, em modelo in vivo, da curcumina administrada em suspensão de iogurte na ausência e na presença de piperina. 2014.

BASHO, S. M.; BIN, M. C. Propriedades dos alimentos funcionais e seu papel na prevenção e controle da hipertensão e diabetes. Interbio v.4 n.1 2010 - ISSN 19813775 .

CAMPION, J.; ALFREDO, M. Ketoconazole, an antifungal agent, protects against adiposity induced by a cafeteria diet. New York, 2003.

FERREIRA, S. R. G. Alimentação, nutrição e saúde: avanços e conflitos da modernidade. Cienc. Cult. vol.62 no.4 São Paulo Oct. 2010.

HAMAGUCHI, T.; ONOL, K.; YAMADA, M.; Curcumin and Alzheimer's Disease. CNS neuroscience and therapeutics, Oxford.v.16, n.5, p.285-297, Oct. 2010.

NAM, S.M.; CHOI. J.H.; YOO.D.Y.; KIM, W.; JUNG, H.Y.; KIM, J.W.; YOO, M.; LEE, S.; KIM, C.J.; YOON, Y.S.; HWANG, I.K. Effects of Curcumin (Curcuma longa) on learning and spatial memory as well as cell proliferation and neuroblastdifferentiation in adult and agedmice by upregulating brain-derived neurotrophicfactor and CREB signaling. Journal of Medicinal Food, Larchmont v.17, n.6, p.641 - 649, Jun. 2014.

QURESHI, S.; SHAH, A. H.; AGEEL, A. M. Toxicity studies on Alpiniagalanga and Curcuma longa. Planta medica, v. 58, n. 02, p. 124-127, 1992.

PACHECO, MTB; SGARBIERI, V. C. Revisão: alimentos funcionais fisiológicos. brazilian Journal of food technology, v. 2, n. 2, p. 7-19, 1999.

PIVA, Pierre; BERNARDI, Daniela Miotto. Administração de Melissa Officinalis para ratos alimentados com dieta de cafeteria: Efeito sobre glicemia sérica e crescimento. 2016.

ROSSI, L.; MAZZITELLI, S.; ARCIELLO, M.; CAPO, C.R.; ROTILIO, G. Benefits from dietary polyphenols for brain aging and Alzheimer's disease. Neurochemical Research, Nova York, v. 33, n.12, p.2390-2400, Dec. 2008

SARTORELLI, Daniela Saes; FRANCO, Laércio Joel. Tendências do diabetes mellitus no Brasil: o papel da transição nutricional. Cad Saúde Pública, v. 19, n. 1, p. 29-36, 2003.

VIANA, Máilla Rebouças; RODRIGUEZ, Tânia T. Complicações cardiovasculares e renais no diabetes mellitus. Revista de Ciências Médicas e Biológicas, v. 10, n. 3, p. 290-296, 2011. 
VILELA, Carlos Alberto Almeida; ARTUR, Patrícia Oliveira. Secagem do açafrão (Curcuma longa L.) em diferentes cortes geométricos. Ciência e Tecnologia de Alimentos, v. 28, n. 2, p. 387-394, 2008.

WICKENBERG, Jennie; INGEMANSSON, Sandra Lindstedt; HLEBOWICZ, Joanna. Effects of Curcuma longa (turmeric) on post prandial plasma glucose and insulin in healthy subjects. Nutrition journal, v. 9, n. 1, p. 43, 2010. 